Article

\title{
Numerical Analysis of Urine Flow with Multiple Sizes of Double-J Stents
}

\author{
Hyoung-Ho Kim ${ }^{1,+}{ }^{\oplus}$, Kyung-wuk Kim ${ }^{2,+}$, Young Ho Choi ${ }^{3, * \mathbb{D}}$, Seung Bae Lee ${ }^{4}$ and Yasutaka Baba ${ }^{5}$ \\ 1 School of Mechanical Engineering, Gyeongnam National University of Science And Technology, \\ Gyeongnam, Jinju 52725, Korea; khh106@gntech.ac.kr \\ 2 Department of Mechanical Engineering, Soongsil University, Seoul, 06978 Korea; thecoming87@naver.com \\ 3 Department of Radiology, Seoul National University, Boramae Hospital, Seoul 07061, Korea \\ 4 Department of Urology, Seoul National University, Boramae Hospital, Seoul 07061, Korea; \\ urseungbaelee@gmail.com \\ 5 Department of Radiology, Saitama medical University, Hidaka-City 1397-1, Japan; \\ y_baba@saitama-med.ac.jp \\ * Correspondence: cyho50168@naver.com \\ + Hyoung-Ho Kim and Kyung-wuk Kim contributed equally to this work.
}

Received: 7 June 2020; Accepted: 19 June 2020; Published: 23 June 2020

\begin{abstract}
This study investigated which sizes of double-J stents are more effective in achieving an acceptable urine flow through stenotic and stented ureters. Sixty four computational fluid dynamics models of the combinations of two different gauge ureters $(4.57 \mathrm{~mm}$ and $5.39 \mathrm{~mm}$ in diameter) with four different levels of ureteral and four different sizes of double-J stents were developed for the numerical analysis of urine flow in the ureter. Luminal, extraluminal, and total flow rates along the ureter were measured, and the flow patterns around the ports and side holes were investigated. For the 4.57-mm ureter, the total flow rate for each gauge of stent was $23-63 \mathrm{~mL} / \mathrm{h}(5 \mathrm{Fr}), 20-47 \mathrm{~mL} / \mathrm{h}$ (6 Fr), $17-35 \mathrm{~mL} / \mathrm{h}(7 \mathrm{Fr})$, and $16-26 \mathrm{~mL} / \mathrm{h}(8 \mathrm{Fr})$ and for the $5.39-\mathrm{mm}$ ureter, the total flow rate for each gauge of stent was $43-147 \mathrm{~mL} / \mathrm{h}(5 \mathrm{Fr}), 36-116 \mathrm{~mL} / \mathrm{h}(6 \mathrm{Fr}), 29-92 \mathrm{~mL} / \mathrm{h}(7 \mathrm{Fr})$, and $26-71 \mathrm{~mL} / \mathrm{h}$ (8 Fr). With a $74 \%$ stenosis, all stents allowed a low flow rate, and the differences in flow rates between the stents were small. At the other levels of stenosis, $5 \mathrm{Fr}$ stents allowed greater flow rates than the $8 \mathrm{Fr}$ stents. The luminal flow rate increased just before the area of stenosis and decreased after the stenosis because of the increase and decrease in the luminal flow through the side holes before and after the stenosis. Therefore, a larger double-J stent is not favorable in achieving an acceptable urine flow through the stenotic and stented ureters. The results in this study could not be necessarily correlated with clinical situation because peristalsis, viscosity of the urine and real format of the ureter were not considered in our model. In vivo experiments are necessary for confirmation of our findings. Double J stents are commonly used in the ureteral stenosis or occlusion, especially due to ureter stones which obstruct the flow of urine. Clinicians choose the size of double J stent on the basis of their clinical experience. Here, we tried to know which sizes of double J stents are better for sufficient urine flow. According to various documents that try to determine the optimal shape of double J stents to increase the urine flow through the ureter, mostly bigger stent is recommended to occur maximum urine flow. However, in case of ureter with stenosis or occlusion, the right size of the double J stent may vary depending on the degree of stenosis in the ureter. To find appropriate stent size for the ureter with stenosis, computational fluid dynamics was conducted. This study shows that smaller diameter stents are more appropriate than larger diameter stents depending on the situation.
\end{abstract}

Keywords: ureter; double-J stent; urine flow; computational fluid dynamics 


\section{Introduction}

Urine is formed in the kidneys, and it flows through the renal pelvis and the ureter to the bladder with the help of hydrodynamic pressure and peristalsis [1,2]. If a focal or segmental lesion develops in the ureter, a urinary disturbance can occur. This disturbance can be relieved through a urinary diversion, such as with a percutaneous nephrostomy using a drainage tube [3]. Another way to solve the problem is to use ureter stents. Currently, plastic stents made of polyurethane are commonly used along with metallic stents [4-8]. A double-J stent is a plastic stent and it consists of a shaft with coils on both ends, with multiple side holes $[9,10]$. It is used in the upper urinary system in cases of ureteral stenosis or occlusion caused by a ureter stone or extrinsic tumor. The placement of a double-J stent in the extrinsic tumor involving the ureter does not guarantee effective urine flow as the tumor compression of the stent often makes fluid drainage outside the stent impossible, and the use of a double-J stent in the tumor can result in stent failure in many cases [11]. In contrast, the placement of a double-J stent in the case of a ureter stone is effective in maintaining urine flow as urine flow is allowed through and around the stent.

In a clinical setting, the 5-, 6-, 7-, and 8-Fr double-J stents are used for ureter stones before and after lithotripsy. The selection of size depends on the clinician's experience based on the possible urine flow rate through the stent. Brewer et al. [12] reported that luminal flow is directly proportional to the internal diameter of the stent, and extraluminal flow does not correlate with the external diameter of the stent once a 7-Fr size is reached although it is proportional to the external diameter. In this study, we investigated which size of double-J stent is better at achieving an acceptable urine flow through the stented ureter using computational fluid dynamics (CFD) to determine the total flow, the sum of luminal and extraluminal flow. We developed a curved ureter model based on human anatomy [13]. Sixty-four CFD models of the combinations of two different gauge ureters (4.57-mm diameter and 5.39-mm diameter) with four levels of ureteral stenosis $(0 \%, 33 \%, 52 \%$, and $74 \%)$ and different sizes of double-J stents with different numbers of side holes were used for the numerical analysis of urine flow in stenotic and stented ureters.

\section{Materials and Methods}

A CFD model for the numerical analysis was composed of a ureter connected to a renal pelvis and a bladder, and a double-J stent (Figure 1). The ureter was made based on the two-dimensional axial computed tomography image data of human anatomies, including the kidney, ureter, and bladder, of 19 males into 15 equal sections perpendicular to the direction in which the patient was lying (z-axis), as shown in Figure 1. The beginning and end points of the ureter were separated into the cross-section of the renal pelvis and the ureter and that of the ureter and the bladder.

Figure 1 shows the ureter shape of each section of Patient 1 . The area of each separated cross-section was measured to calculate the diameter when the cross-section was assumed to be circular. This method was repeated for 18 additional patients. S. $1-1^{\prime}$ is segment $1-1^{\prime}$. The mean diameter of each section from the 19 patients are shown in Table 1. The STDEVP function calculated the standard deviation based on the entire population given as arguments [14]. The standard deviation is a measure of how widely the values are dispersed from the average value. The distance between the center points of each cross-section was measured similarly to the method mentioned above. Table 2 presents the measured distance for Patient 1. S. 1-2 is the distance between segments 1-1' and 2-2'. Similarly, measurements were made on the $\mathrm{x}, \mathrm{y}$, and $\mathrm{z}$ axes between sections of the other 18 patients. According to the measured information, a ureter model was constructed by averaging the data of the ureteral lengths and diameters from the patients. The model was curved and 226.21-mm long, and the proximal end of the ureter was connected to the renal pelvis, which has a conical shape. The distal end of the ureter was connected to the bladder, which has a dome shape. The base of the renal pelvis and the bladder was round and $40 \mathrm{~mm}$ in diameter. The height of the renal pelvis and bladder was $15.5 \mathrm{~mm}$. The ureter was tubular and $4.57 \mathrm{~mm}$ in diameter. Another ureter model was made with a $5.39-\mathrm{mm}$ ureter diameter in view of the 8-Fr stents. A double-J stent (DJS) model inserted into the ureter using the ureteral data collected from 
the patients was developed using SolidWorks software (Dassault Systèmes SE, Vélizy-Villacoublay, France) and ICEM CFD software (version 16.2; Ansys, Inc., Canonsburg, PA, USA). The DJS model was based on the Cook Medical stent (Cook Group Inc., Bloomington, IN, USA). This DJS model consists of two coils with a J-shape and a shaft. The shaft has several side holes that provide a flow diversion from the stent to the ureter or vice versa, and the coiled ends have various side holes which play a role in urine flow in and out of the stent in the kidney and the bladder, as shown in Figure 2.

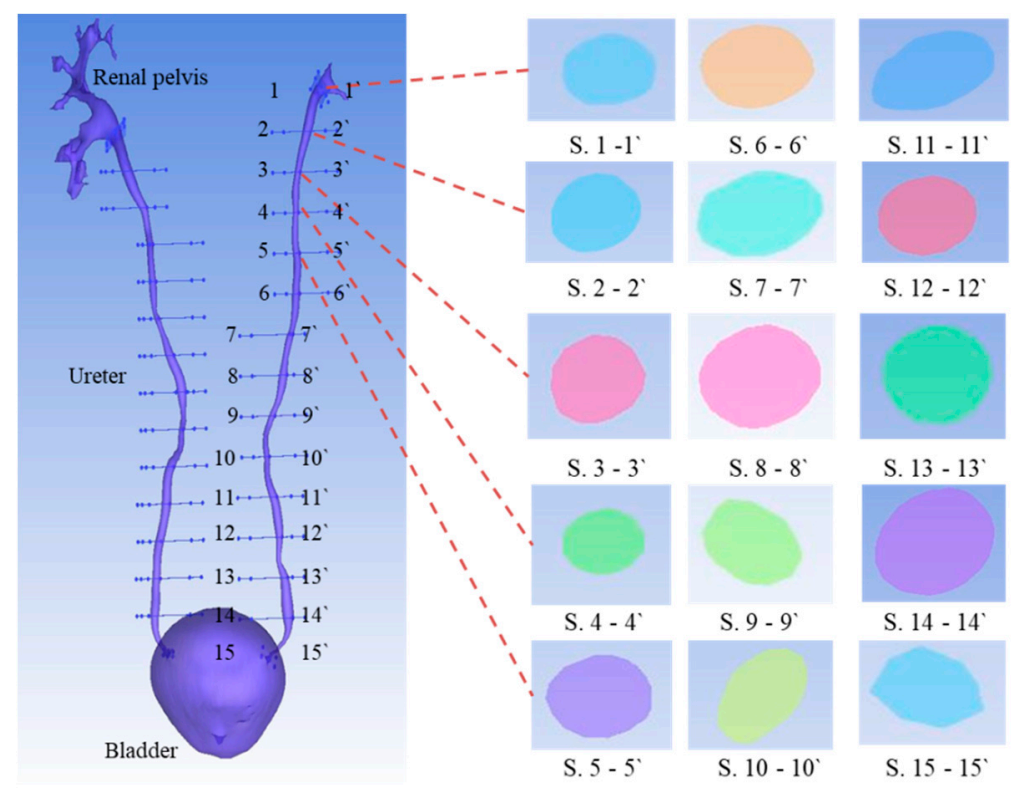

Figure 1. Cross-sectional segments of the ureter between the renal pelvis and the bladder (Patient 1).

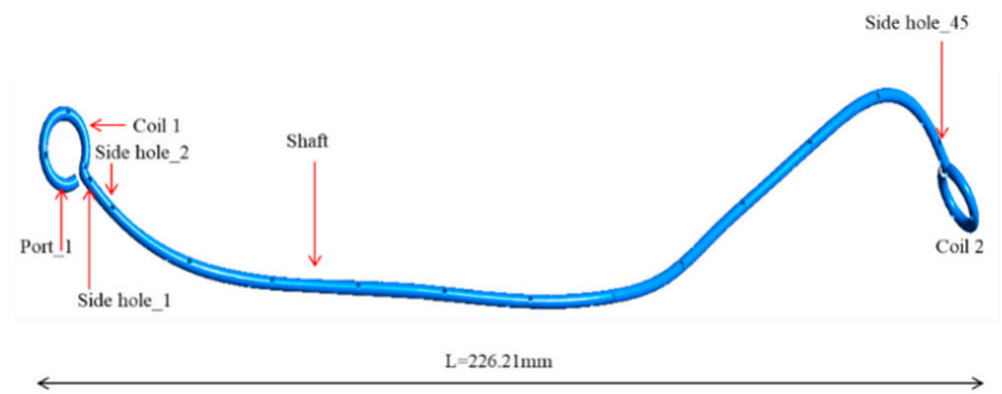

Figure 2. Schematic of the DJS model. 
Table 1. Measured distance between each segment of patients.

\begin{tabular}{|c|c|c|c|c|c|c|c|c|c|c|c|c|c|c|c|c|c|c|c|c|c|}
\hline $\begin{array}{l}\text { Case } \\
\text { Segment }\end{array}$ & 1 & 2 & 3 & 4 & 5 & 6 & 7 & 8 & 9 & 10 & 11 & 12 & 13 & 14 & 15 & 16 & 17 & 18 & 19 & $\begin{array}{l}\text { Mean } \\
\text { Dia }\end{array}$ & STDEVP \\
\hline S. 1-1 & 4.88 & 4.20 & 6.19 & 5.13 & 5.18 & 5.46 & 4.79 & 6.89 & 4.99 & 6.07 & 4.70 & 6.31 & 7.04 & 6.85 & 7.09 & 5.63 & 4.21 & 5.60 & 6.90 & 5.69 & 0.941 \\
\hline S. 2-2 & 5.73 & 4.54 & 5.80 & 6.77 & 5.30 & 4.87 & 4.27 & 6.35 & 5.25 & 5.98 & 3.69 & 5.88 & 6.13 & 4.33 & 4.94 & 6.13 & 3.69 & 5.94 & 4.57 & 5.27 & 0.885 \\
\hline S. 3-3 & 3.79 & 4.71 & 5.17 & 5.61 & 4.50 & 4.47 & 5.23 & 5.23 & 3.66 & 4.57 & 3.30 & 5.19 & 5.16 & 4.23 & 4.54 & 3.66 & 3.32 & 3.74 & 4.23 & 4.44 & 0.692 \\
\hline S. $4-4$ & 3.40 & 4.81 & 3.16 & 4.71 & 4.12 & 4.03 & 4.27 & 3.11 & 3.40 & 3.10 & 3.27 & 4.94 & 4.30 & 4.52 & 4.16 & 4.83 & 2.94 & 3.79 & 4.38 & 3.96 & 0.651 \\
\hline S. $5-5$ & 4.15 & 4.64 & 3.41 & 5.37 & 5.24 & 3.19 & 3.70 & 3.67 & 4.28 & 3.37 & 3.86 & 5.42 & 4.31 & 4.33 & 4.50 & 2.61 & 3.95 & 3.22 & 4.23 & 4.08 & 0.743 \\
\hline S. 6-6 & 4.43 & 6.05 & 3.92 & 3.96 & 4.52 & 3.67 & 3.94 & 4.73 & 4.49 & 3.99 & 4.11 & 4.16 & 2.61 & 5.31 & 4.91 & 2.96 & 3.75 & 3.95 & 5.24 & 4.25 & 0.780 \\
\hline S. $7-7$ & 3.66 & 4.64 & 4.48 & 4.42 & 4.35 & 3.65 & 3.84 & 4.57 & 3.81 & 4.30 & 4.10 & 4.52 & 3.35 & 5.89 & 5.31 & 4.57 & 3.66 & 4.16 & 5.89 & 4.38 & 0.686 \\
\hline S. $8-8$ & 4.57 & 6.08 & 4.25 & 4.39 & 4.14 & 2.63 & 4.91 & 2.85 & 4.67 & 4.09 & 5.24 & 4.52 & 3.08 & 5.72 & 6.18 & 4.50 & 3.47 & 4.16 & 5.62 & 4.48 & 0.988 \\
\hline S. 9-9 & 3.29 & 5.19 & 4.06 & 3.86 & 4.56 & 4.34 & 4.10 & 3.11 & 3.36 & 4.14 & 4.72 & 4.30 & 4.19 & 6.19 & 6.26 & 2.78 & 4.58 & 2.96 & 6.29 & 4.33 & 0.103 \\
\hline S. $10-10$ & 4.36 & 5.50 & 4.93 & 4.51 & 5.69 & 4.77 & 4.93 & 3.65 & 4.06 & 4.84 & 4.95 & 4.33 & 1.86 & 4.76 & 5.63 & 3.64 & 3.38 & 3.39 & 4.86 & 4.42 & 0.909 \\
\hline S. 11-11 & 5.43 & 3.46 & 5.32 & 5.25 & 4.83 & 2.85 & 5.36 & 4.06 & 5.46 & 5.46 & 5.54 & 5.22 & 3.97 & 5.84 & 6.18 & 3.63 & 3.03 & 4.49 & 5.64 & 4.79 & 0.972 \\
\hline S. $12-12$ & 4.46 & 6.30 & 5.77 & 3.88 & 5.02 & 5.56 & 0.86 & 6.56 & 4.20 & 5.73 & 5.69 & 3.89 & 3.53 & 5.68 & 6.02 & 4.18 & 4.32 & 4.10 & 5.94 & 4.83 & 1.30 \\
\hline S. 13-13' & 4.87 & 5.81 & 5.49 & 3.96 & 5.43 & 8.84 & 4.85 & 3.29 & 5.11 & 4.41 & 3.75 & 3.85 & 4.79 & 5.10 & 5.81 & 7.44 & 5.01 & 1.50 & 4.92 & 4.96 & 1.48 \\
\hline S. $14-14$ & 6.69 & 7.74 & 3.81 & 5.88 & 6.20 & 5.16 & 2.07 & 2.90 & 6.42 & 4.43 & 4.28 & 5.91 & 5.31 & 5.72 & 5.60 & 3.74 & 4.55 & 4.64 & 5.99 & 5.11 & 1.34 \\
\hline S. $15-15$ & 2.21 & 5.20 & 1.48 & 3.72 & 3.79 & 2.52 & 2.20 & 1.46 & 3.38 & 4.20 & 4.97 & 4.08 & 3.88 & 3.43 & 5.65 & 4.85 & 4.87 & 2.61 & 3.70 & 3.59 & 1.20 \\
\hline $\begin{array}{c}\text { Mean } \\
\text { Dia. }\end{array}$ & & & & & & & & & & & & & & & & & & & & 4.57 & \\
\hline
\end{tabular}

Table 2. Measured distance between each segments.

\begin{tabular}{cccc}
\hline & $\mathbf{X}(\mathbf{m m})$ & $\mathbf{Y}(\mathbf{m m})$ & $\mathbf{Z}$ (mm) \\
\hline Total length & -23.0 & 29.7 & -226 \\
S. 1-2 & -7.89 & -5.37 & -16.5 \\
S. 2-3 & -5.87 & -1.36 & -16.1 \\
S. 3-4 & -1.73 & -0.63 & -16.1 \\
S. 4-5 & -0.03 & -1.32 & -16.1 \\
S. 5-6 & -1.22 & -3.91 & -16.1 \\
S. 6-7 & -3.80 & -4.23 & -16.1 \\
S. 7-8 & -4.94 & -2.35 & -16.1 \\
S. 8-9 & -6.38 & 1.98 & -16.1 \\
S. 9-10 & -1.27 & 13.9 & -16.1 \\
S. 10-11 & 5.42 & 15.8 & -16.1 \\
S. 11-12 & 3.52 & 4.89 & -16.1 \\
S. 12-13 & 2.61 & 2.12 & -16.1 \\
S. 13-14 & 2.12 & 4.41 & -16.1 \\
S. 14-15 & -10.5 & 6.84 & -16.1 \\
\hline
\end{tabular}


The DJS model included a shaft in the middle that was as long as the ureter, at $226.21 \mathrm{~mm}$. It had two coils in the ends that were round and $10 \mathrm{~mm}$ in diameter. The sizes of the stents were 5, 6, 7, and $8 \mathrm{Fr}$ with inner diameters of $0.67,1,1.33$, and $1.67 \mathrm{~mm}$, respectively, and outer diameters of $1.67,2$, 2.33 , and $2.67 \mathrm{~mm}$, respectively, with multiple side holes in the shaft and coils. The side holes and end holes in the coils were called ports to differentiate them from the side holes in the shaft. Two different types of stents were made, differentiated by the number and position of the side holes in the shaft. The first type was a stent with 22 side holes placed at a $1-\mathrm{cm}$ intervals and at a $90^{\circ}$ angular position. The other was a stent with 45 side holes placed at a $0.5-\mathrm{cm}$ intervals and at a $90^{\circ}$ angular position. The number of ports in each coil was five, including four side holes and one end hole. The diameter of the side holes and ports, except the end holes, was $1 \mathrm{~mm}$, and the diameter of the end holes in the coils depended on the diameter of the stent.The ureter and the stent were combined, and thus the axis of the ureter was shared with that of the stent, meaning that the ureter and the stent had the same axis. The stent was located in the center of the ureter. A concentric stenosis was made in the middle of the ureter, and it was $15 \mathrm{~mm}$ long.

The degrees of stenosis in the ureter were $0 \%, 33 \%, 52 \%$, and $74 \%$ in area, as shown in Figure 3.
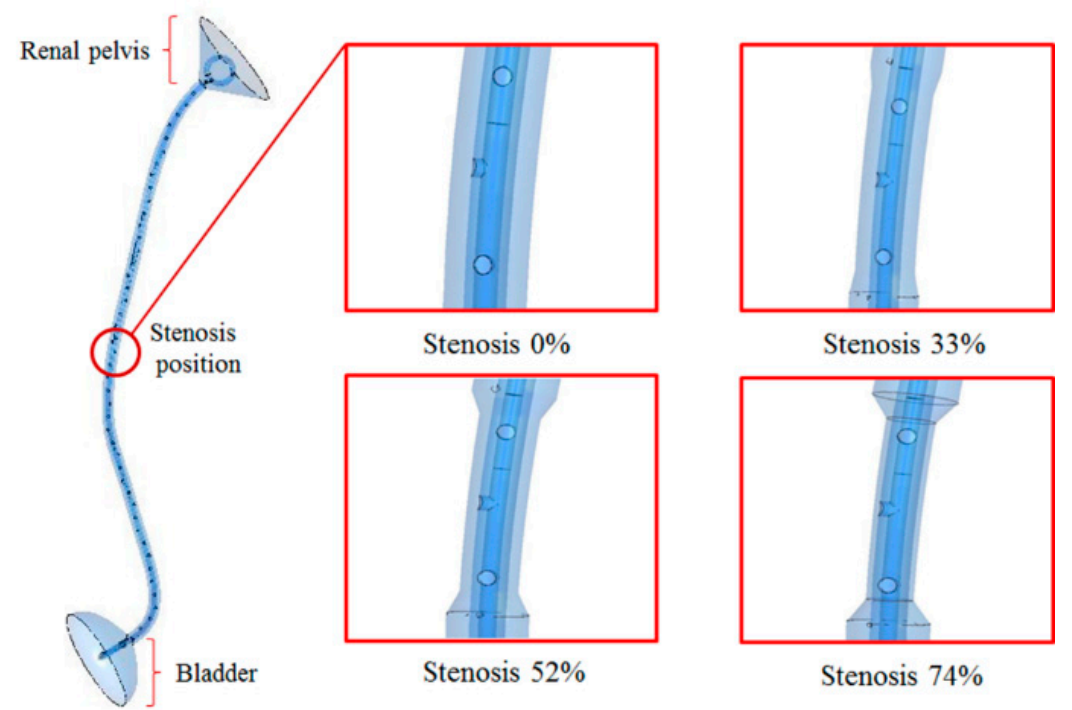

Stenosis $33 \%$

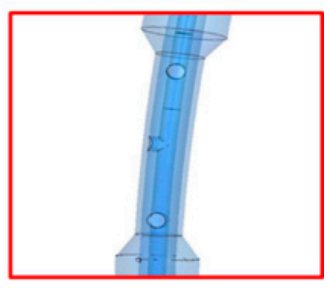

Stenosis $74 \%$

Figure 3. A stented ureter model and four magnified mid-ureters with different stenoses $(0 \%, 33 \%$, $52 \%$, and $74 \%$ ). The diameter of the curved tubular ureter is $4.57 \mathrm{~mm}$ and the stent is a 6-Fr DJS.

Stenosis in the ureter can occur not only in the middle position, but anywhere in the narrow diameter of the ureter [15]. This study assumed the same location and size of stenosis to extend the results of the study to cases in which a previous stenosis occurred, to compare and analyze the effects on the DJS size [16].

The combination of two different curved tubular ureters ( 4.57 and $5.39 \mathrm{~mm}$ ), eight different types of stents (5-8 Fr, each with 22 or 45 side holes), and four different degrees of stenosis in the ureter $(0 \%, 33 \%, 52 \%$, and $74 \%)$ resulted in 64 different stented ureter CFD models for numerical analysis. Table 3 shows the details of the eight different models in a certain diameter ureter with a certain size of double-J stent. In two models with a 4.57-mm ureter, 8-Fr stent, and 74\% stenosis (Cases 7 and 8), no space was found between the inner ureter wall and the outer stent wall.

The mesh generation of the ureter-inserted DJS geometry was conducted using ICEM CFD software. The prism and tetrahedron grid types were used to make the mesh because of the complex shape of the model. The unconstructed grid systems of the ureter-inserted DJS are shown in Figure 4. The total grid elements and node range of the model were $9.579 \times 10^{6}-13.53 \times 10^{6}$ elements and $3.049 \times 106-19.52 \times 106$ nodes, respectively. To check the mesh sensitivity, a mesh independency test 
was performed for Case 1 (tubular type, $4.57 \mathrm{~mm}$, 5-Fr size, without ureteral stenosis), as shown in Figure 5.

Table 3. Eight different models in a 4.57/5.39 mm ureter with a 5-8Fr double J stent [16].

\begin{tabular}{cccccc}
\hline Case & Ureter & Number of Side Holes & Angular Position of Side Holes & Interval of Side Holes (cm) & Ureteral Stenosis \\
\hline 1 & Tubular & 22 & $0^{\circ}, 90^{\circ}, 180^{\circ}, 270^{\circ}$ & 1.0 & $0 \%$ \\
2 & Tubular & 45 & $0^{\circ}, 90^{\circ}, 180^{\circ}, 270^{\circ}$ & 0.5 & $0 \%$ \\
3 & Tubular & 22 & $0^{\circ}, 90^{\circ}, 180^{\circ}, 270^{\circ}$ & 1.0 & $33 \%$ \\
4 & Tubular & 45 & $0^{\circ}, 90^{\circ}, 180^{\circ}, 270^{\circ}$ & 0.5 & $33 \%$ \\
5 & Tubular & 22 & $0^{\circ}, 90^{\circ}, 180^{\circ}, 270^{\circ}$ & 1.0 & $52 \%$ \\
6 & Tubular & 45 & $0^{\circ}, 90^{\circ}, 180^{\circ}, 270^{\circ}$ & 0.5 & $74 \%$ \\
7 & Tubular & 22 & $0^{\circ}, 90^{\circ}, 180^{\circ}, 270^{\circ}$ & 1.0 & $74 \%$ \\
8 & Tubular & 45 & $0^{\circ}, 90^{\circ}, 180^{\circ}, 270^{\circ}$ & 0.5 & \\
\hline
\end{tabular}

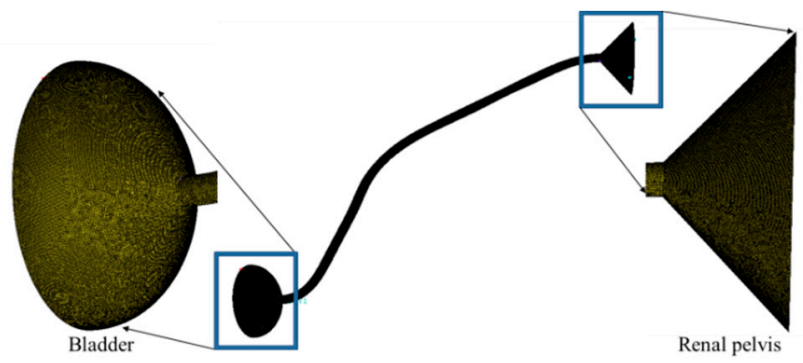

(a) Ureter mesh systems.

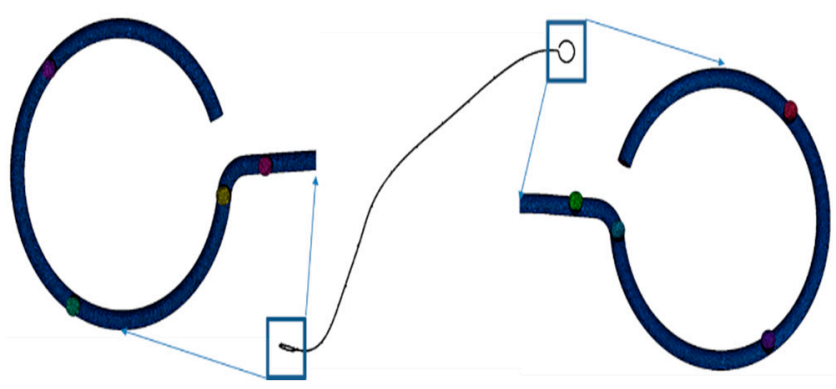

(b) DJS mesh systems.

Figure 4. Mesh composition of the ureter-inserted DJS.

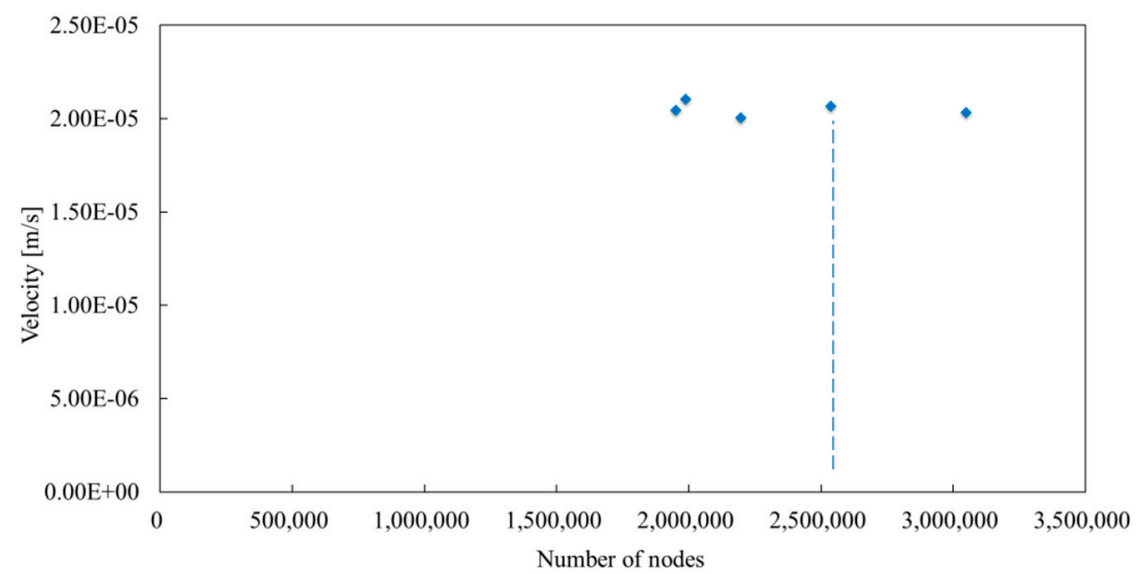

Figure 5. A stented ureter model and four magnified mid-ureters with different stenoses $(0 \%, 33 \%$, $52 \%$, and $74 \%$ ). 
The governing equations for fluid flow and the boundary conditions for numerical analysis in a previous study [16] were also used here. The continuity and momentum equations are as follows:

$$
\begin{gathered}
\frac{\partial u_{j}}{\partial x_{j}}=0 \\
\rho\left(\frac{\partial u_{i}}{\partial t}+u_{j} \frac{\partial u_{i}}{\partial x_{i}}\right)=-\frac{\partial p}{\partial x_{i}}+\eta \frac{\partial}{\partial x_{i}}\left(\frac{\partial u_{i}}{\partial x_{j}}+\frac{\partial u_{j}}{\partial x_{i}}\right)
\end{gathered}
$$

where $\rho, u, \eta$, and $p$ are the density, velocity vector, viscosity, and pressure, respectively. The governing equations were discretized using the finite volume method with CFX 16.2 software (Ansys Inc.) [17]. The boundary condition and the urine viscosity used in the study were the same as in the previous study [16]. Urine is considered an incompressible and Newtonian fluid. If urine is stagnant in one place for a long time, its viscosity and physical properties will change [18]. However, this study focused on urine flow through the DJS and did not consider the change in the physical properties of urine in stagnant situations. Here, we investigated the flow rates and patterns in the urinary system. The flow inside the stent is called the luminal flow, and the flow outside of the stent in the ureter is called the extraluminal flow, as shown in Figure 6. The total flow rate is the sum of the luminal and extraluminal flow rates. The luminal, extraluminal, and total flow rates along the ureter were measured. In addition, the flow patterns around the ports and side holes, especially in the mid-ureter, were analyzed. In subsequent studies, an in vitro experiment was conducted to verify the validity of the simulation results, and a good match was found [19].

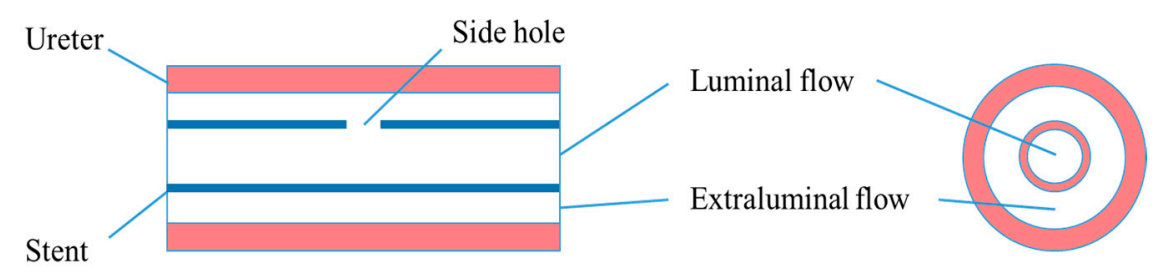

Figure 6. Flow in the stented ureter. Total flow consists of the luminal flow and the extraluminal flow.

\section{Results}

The total flow rate in the 5-Fr double-J stents was $23-63 \mathrm{~mL} / \mathrm{h}$ in the $4.57-\mathrm{mm}$ ureter and $43-147 \mathrm{~mL} / \mathrm{h}$ in the $5.39-\mathrm{mm}$ ureter, and in the 6-Fr double-J stents the flow rate was $20-47 \mathrm{~mL} / \mathrm{h}$ in the $4.57-\mathrm{mm}$ ureter and $36-116 \mathrm{~mL} / \mathrm{h}$ in the $5.39-\mathrm{mm}$ ureter (Figure 7). The total flow rate in the 7-Fr double-J stents was $17-35 \mathrm{~mL} / \mathrm{h}$ in the $4.57-\mathrm{mm}$ ureter and $29-92 \mathrm{~mL} / \mathrm{h}$ in the $5.39-\mathrm{mm}$ ureter, and in the 8 -Fr double-J stents the flow rate was $16-26 \mathrm{~mL} / \mathrm{h}$ in the $4.57-\mathrm{mm}$ ureter and $26-71 \mathrm{~mL} / \mathrm{h}$ in the 5.39-mm ureter.

The total flow rate in the stented ureters with 5-Fr double-J stents was greater than that in the stented ureters with the other sizes of double-J stents.

The total flow rate decreased with the increase in the size of the stents. The total flow rate in the stented ureters without any ureteral stenosis was greater than that in the stented ureters with ureteral stenosis. The total flow rate decreased with the increase in the severity of the stenosis. The $4.57-\mathrm{mm}$ ureter with an 8-Fr double-J stent and $74 \%$ ureteral stenosis did not exhibit an extraluminal flow rate because of the lack of space between the inner ureter wall and the outer stent wall, that is, the absence of extraluminal space. In this case, the luminal flow rate was the total flow rate. The luminal flow rate around the ureteral stenosis in the mid-ureter was different from that in the proximal and distal ureter (Figures 8 and 9).

The luminal flow formed through the fifth port in the renal pelvis and the first side hole in the proximal ureter was maintained in the proximal ureter. The luminal flow rate increased before the stenosis because of the increase in the luminal flow through the side holes before the stenosis. 
Then, it decreased after the stenosis because of the decrease in the luminal flow through the side holes after the stenosis. However, the luminal flow rate was maintained in the distal ureter.

The luminal flow rate was greater when the size of the stent was larger. When a ureteral stenosis became more severe, the luminal flow rate in the proximal and distal ureter decreased and that in the mid-ureter increased. The luminal flow rate in the 5-Fr double-J stents reached $1.2 \mathrm{~mL} / \mathrm{h}$ in the $4.57-\mathrm{mm}$ ureter and $1.2 \mathrm{~mL} / \mathrm{h}$ in the $5.39-\mathrm{mm}$ ureter, and in the 6-Fr double-J stents the flow rate reached $5.9 \mathrm{~mL} / \mathrm{h}$ in the $4.57-\mathrm{mm}$ ureter and $6.1 \mathrm{~mL} / \mathrm{h}$ in the $5.39-\mathrm{mm}$ ureter. The luminal flow rate in the 7-Fr double-J stents reached $11.4 \mathrm{~mL} / \mathrm{h}$ in the $4.57-\mathrm{mm}$ ureter and $14.7 \mathrm{~mL} / \mathrm{h}$ in the $5.39-\mathrm{mm}$ ureter, and in the 8 -Fr double-J stents the flow rate reached $16 \mathrm{~mL} / \mathrm{h}$ in the $4.57-\mathrm{mm}$ ureter and $24 \mathrm{~mL} / \mathrm{h}$ in the $5.39-\mathrm{mm}$ ureter.

The extraluminal flow rate was greater than the luminal flow rate in the proximal and distal ureter (Figures 10 and 11). In the mid-ureter, the luminal flow rate was greater than the extraluminal flow rate when the ureteral stenosis was $74 \%$ and the size of the double-J stent was 8 Fr. However, in the remaining cases, the extraluminal flow rate was greater than the luminal flow rate.

No significant flow into or out of the stent was found except for the first and last side holes in the proximal and distal ureter. The inflow and outflow to the stent were demonstrated before and after the stenosis. Around a ureteral stenosis, the flows into and out of a stent before and after the stenosis were shown.

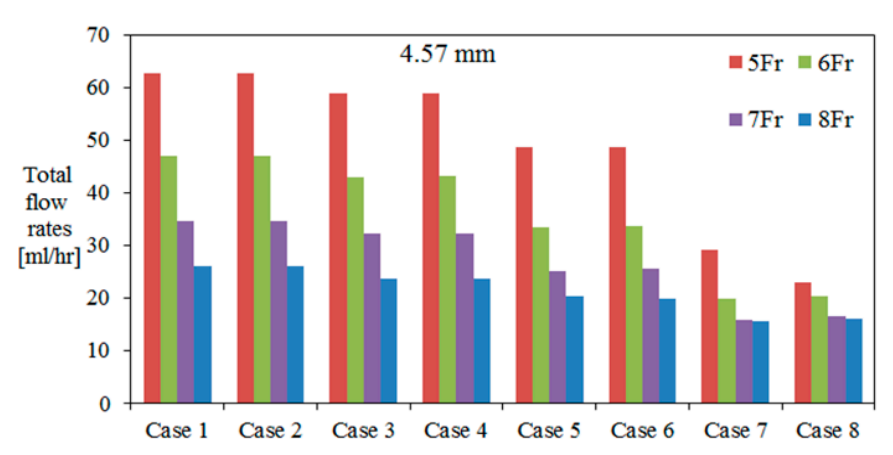

(a) $4.57 \mathrm{~mm}$.

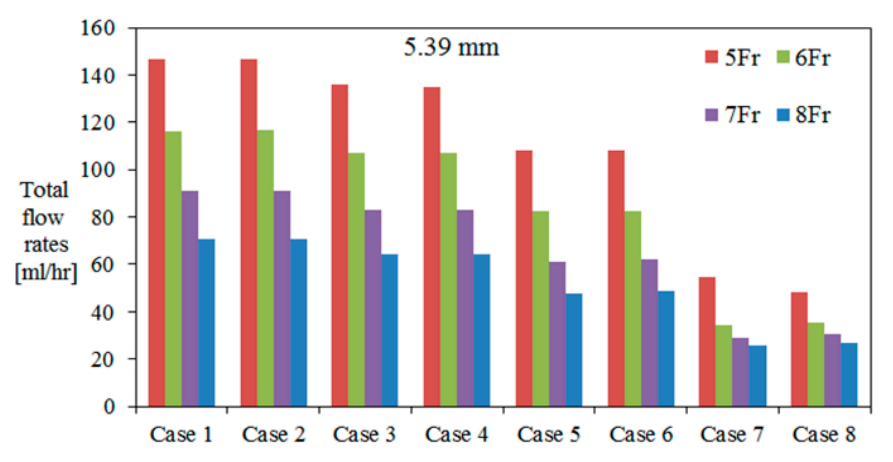

(b) $5.39 \mathrm{~mm}$.

Figure 7. Total flow rate in the models of the 4.57 and $5.39 \mathrm{~mm}$ ureters (Cases 1-8 are defined in Table 3). 


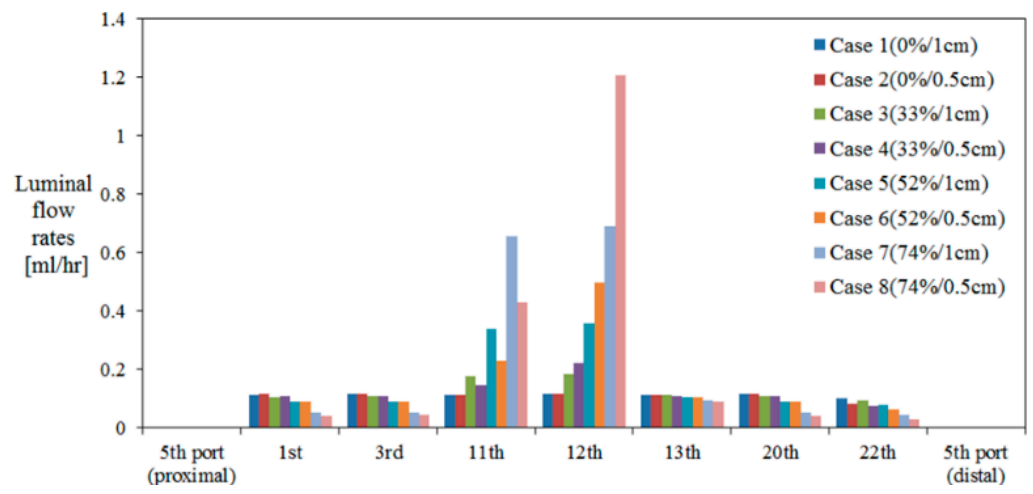

(a) $5 \mathrm{Fr}$.

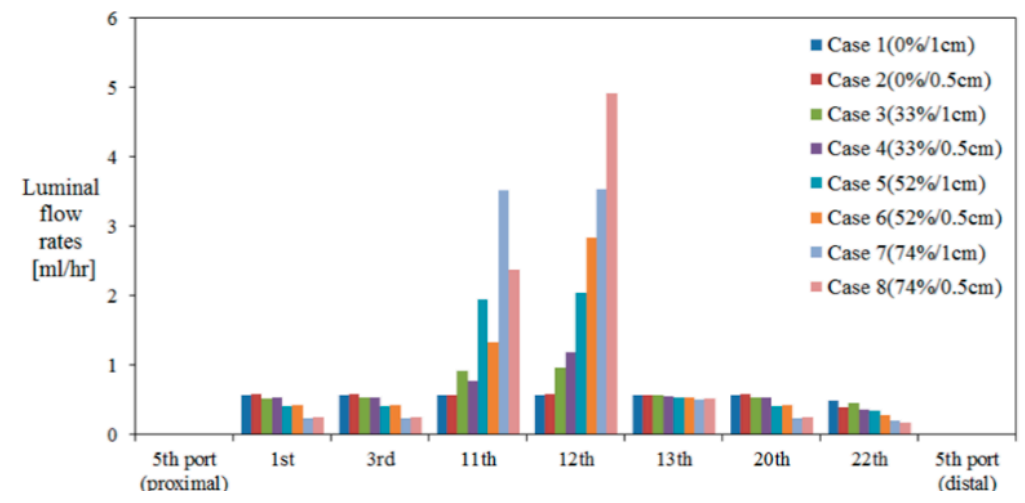

(b) $6 \mathrm{Fr}$.

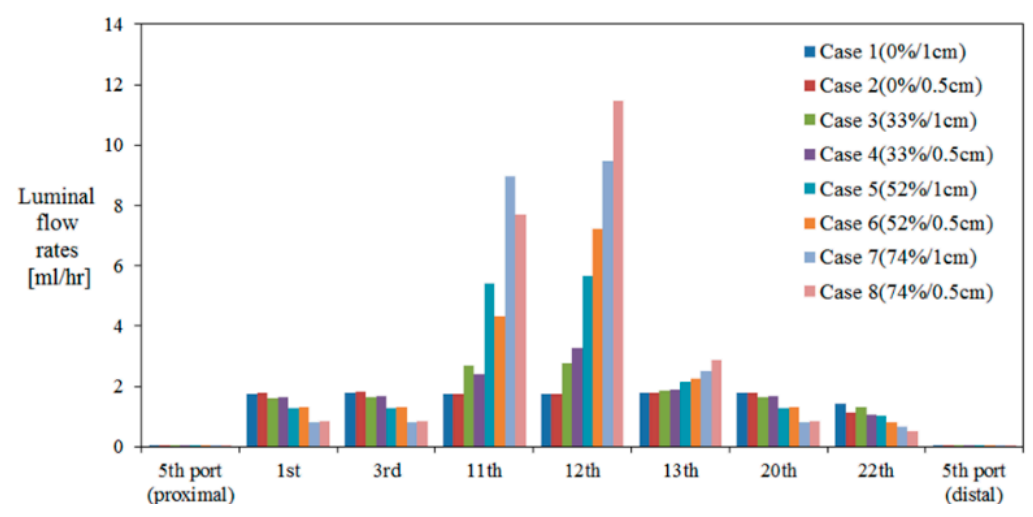

(c) 7 Fr.

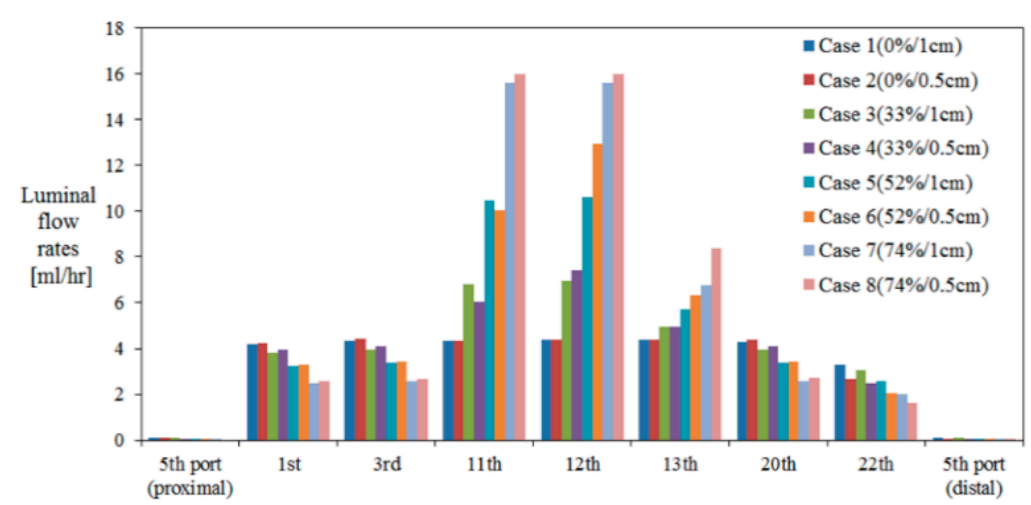

(d) 8 Fr.

Figure 8. Luminal flow rate in the models of the $4.57 \mathrm{~mm}$ ureter. 


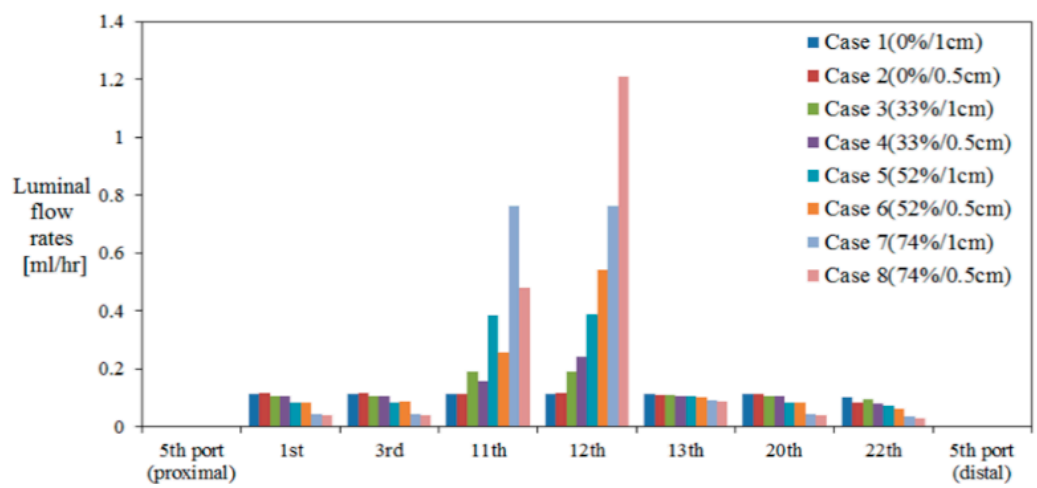

(a) $5 \mathrm{Fr}$.

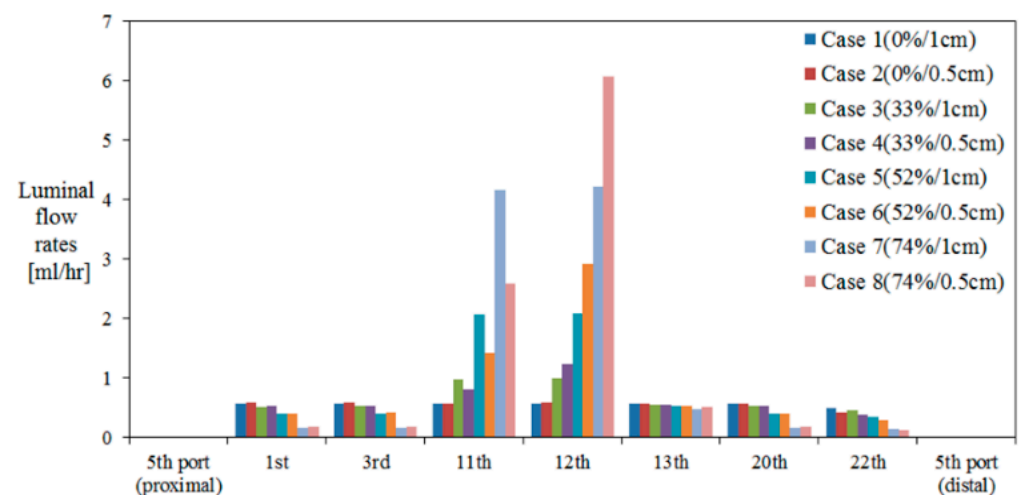

(b) $6 \mathrm{Fr}$.

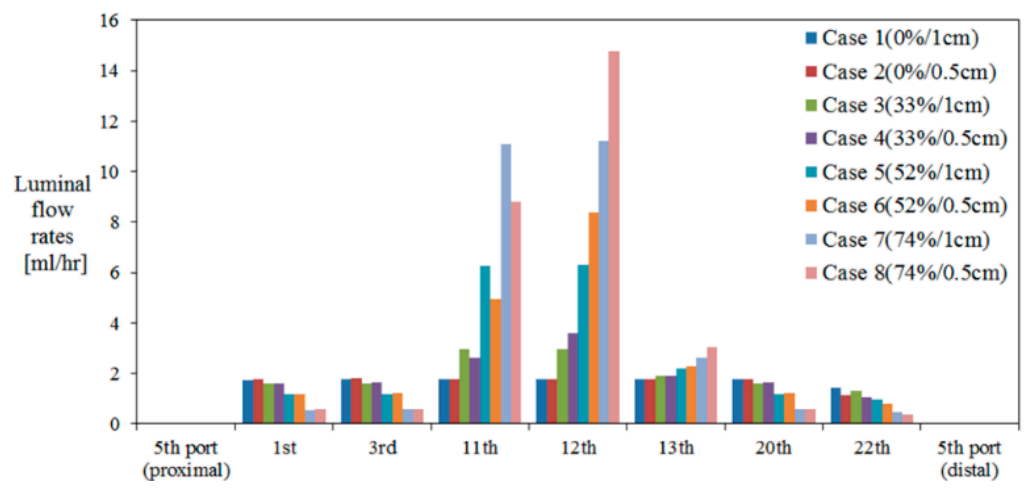

(c) 7 Fr.

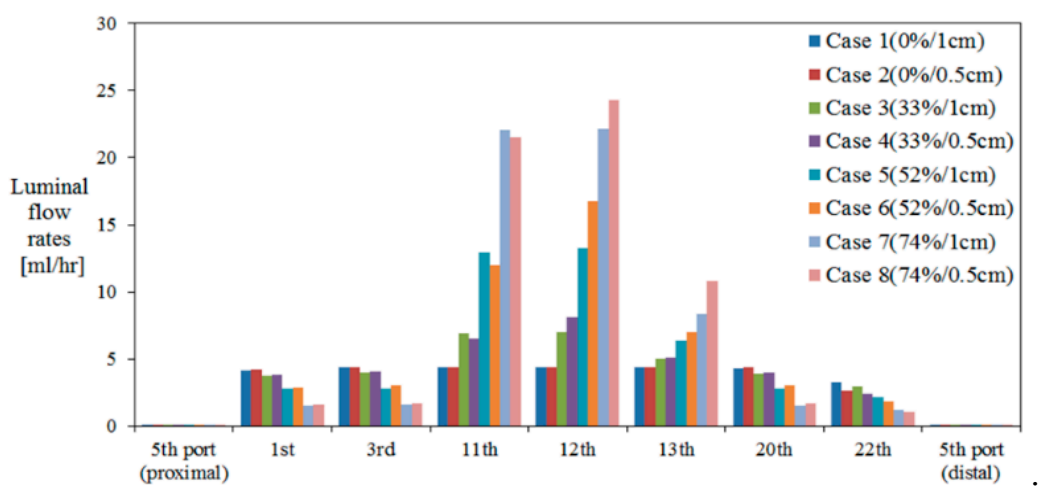

(d) 8 Fr.

Figure 9. Luminal flow rate in the models of the $5.39 \mathrm{~mm}$ ureter. 


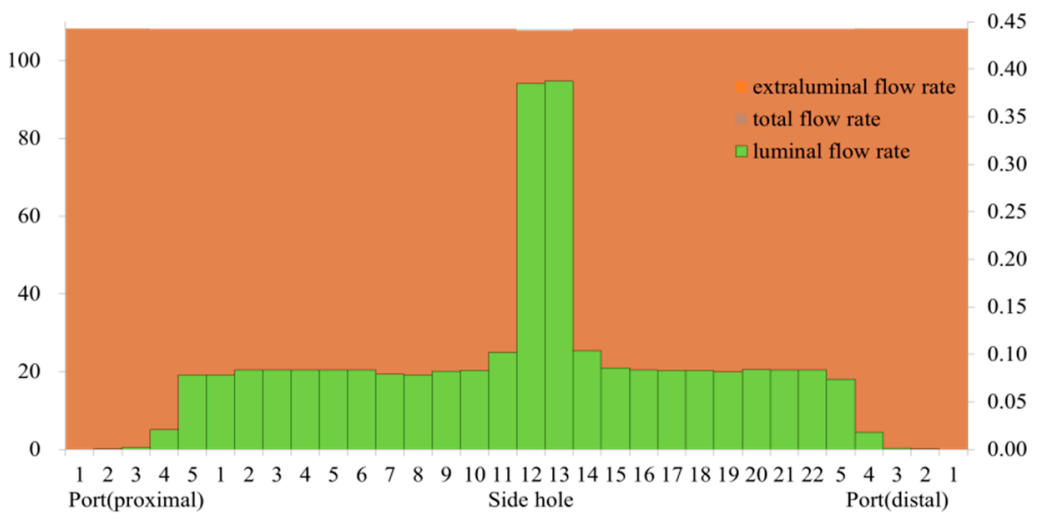

(a) 5 Fr.

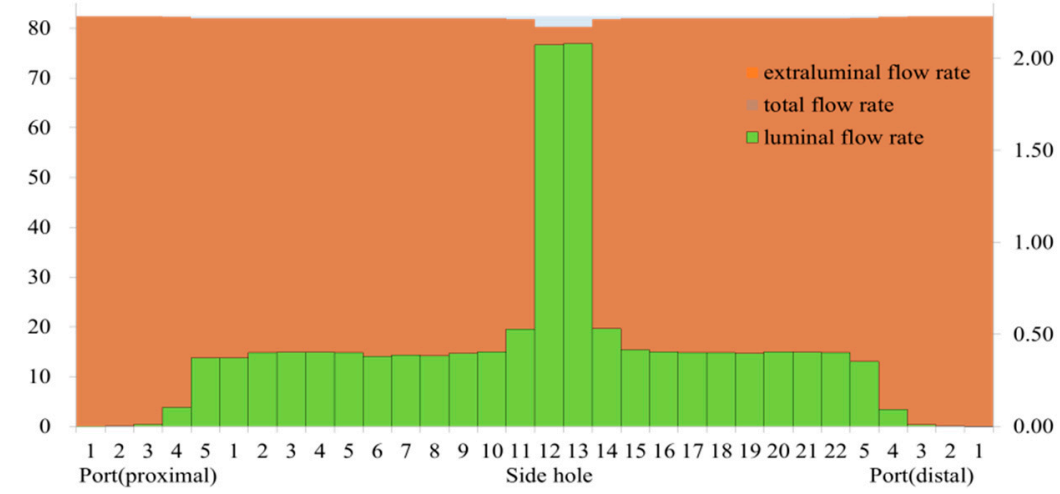

(b) 6 Fr.

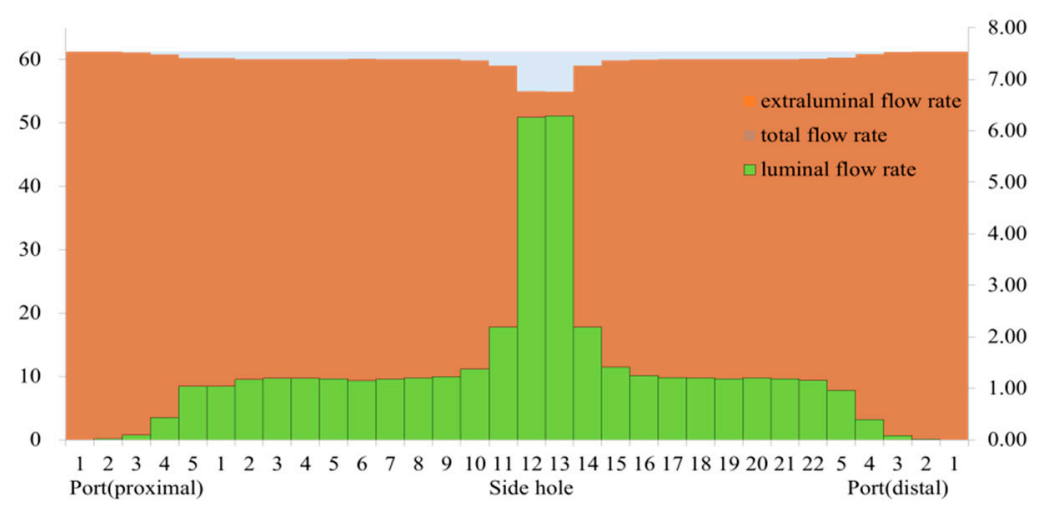

(c) 7 Fr.

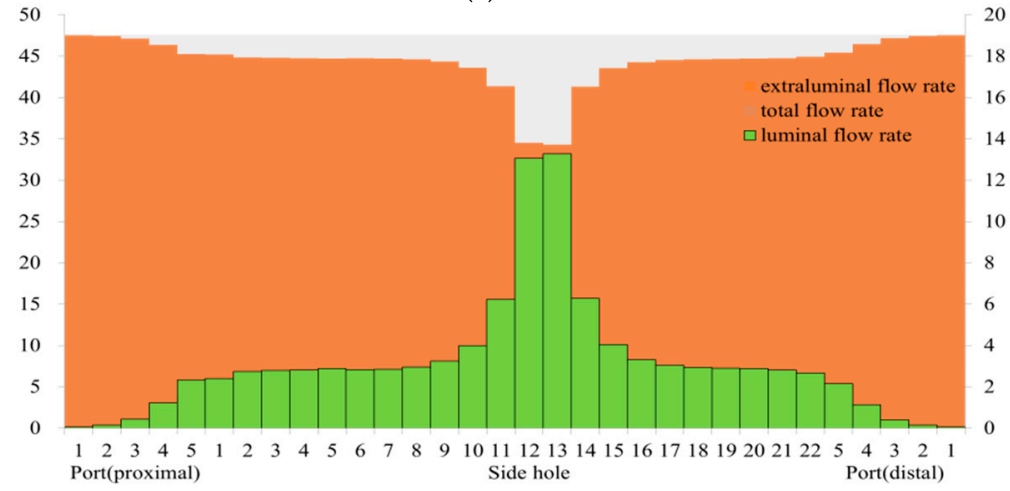

(d) $8 \mathrm{Fr}$.

Figure 10. Luminal, extraluminal, and total flow rates in the $5.39 \mathrm{~mm}$ ureter in Case $5(1 \mathrm{~cm}$ side holes, $52 \%$ stenosis). 


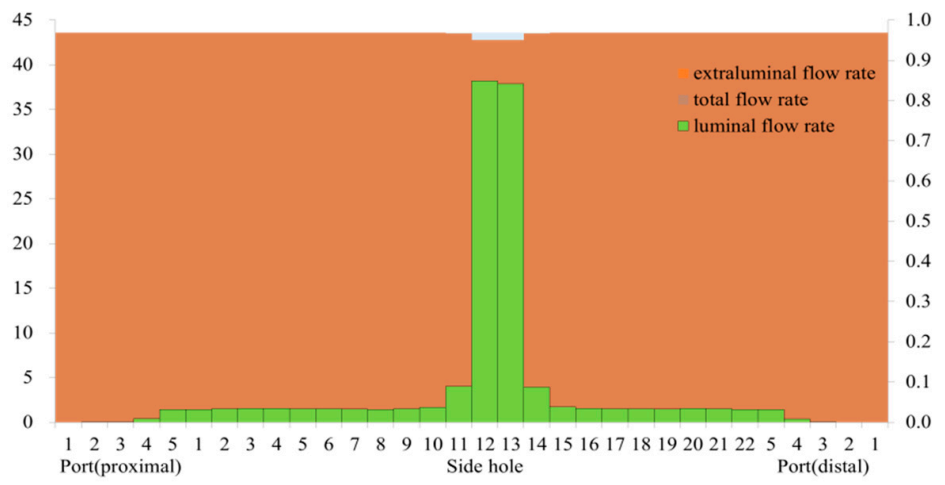

(a) $5 \mathrm{Fr}$.

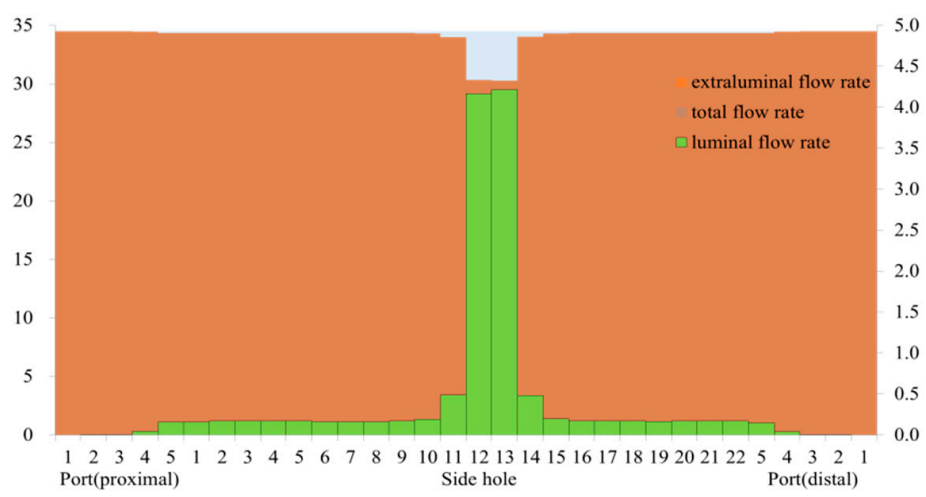

(b) 6 Fr.

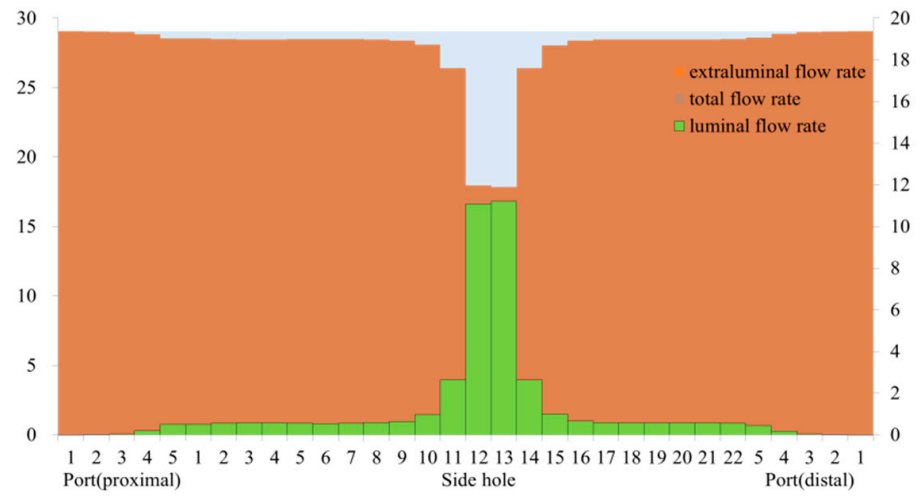

(c) $7 \mathrm{Fr}$.

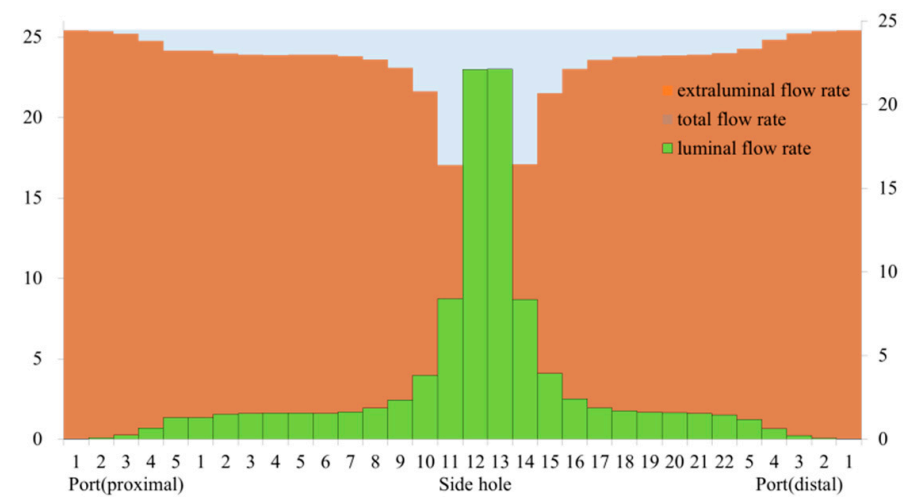

(d) 8 Fr.

Figure 11. Luminal, extraluminal, and total flow rates in the $5.39 \mathrm{~mm}$ ureter in Case $7(1 \mathrm{~cm}$ side holes, $74 \%$ stenosis). 


\section{Discussion}

A double-J stent is used along with metallic stents in ureteral stenosis or occlusion [4-8]. The goal in using a double-J stent is to obtain a route for urine flow and to achieve a sufficient and acceptable urine flow through the stented ureter. The indwelling pigtail ureteral stent has proven its efficacy in maintaining ureteral patency in many cases, and it is widely used as an adjunct to extracorporeal shock wave lithotripsy. Here, we limited the study to cases of ureter stones. Although malignant ureteral obstruction is treated with a double-J stent, the patency rate has been poor [20].

Normal urine flow through the ureter is formed with the help of peristalsis and hydrodynamic forces $[1,2]$. Peristalsis occurs about five to six times per minute in a normal condition, but it is affected by physical changes in the ureter or by the placement of a double-J stent. Initially, peristalsis can be activated to overcome a limited urine output to the bladder, but as time goes on, the frequency of peristalsis may lessen and finally zero-out [21-23]. This condition is a great obstacle in maintaining urine flow through the ureter.

The critical evaluation for the clinical application of a double-J stent should be whether the stent could get a sufficient and acceptable urine flow through a stented ureter and which stent size is the best in achieving this. No fluid dynamics studies have been conducted yet on the proper size in the application of a double-J stent.

There is a question of whether we could achieve a sufficient urine flow through a stented ureter with only a luminal flow. The peak values of the luminal flow rates in this study were $16 \mathrm{~mL} / \mathrm{h}$ and $24 \mathrm{~mL} / \mathrm{h}$ in the $4.57 \mathrm{~mm}$ and $5.39 \mathrm{~mm}$ ureters, respectively, obtained with a $74 \%$ ureteral stenosis and an 8-Fr double-J stent. The urine output over $24 \mathrm{~h}$ was $384 \mathrm{~mL}$ and $576 \mathrm{~mL}$ with the peak flow values, which were not sufficient or acceptable urine flows in normal daily living. Achieving the goal in the clinical application of a double-J stent is difficult with only a luminal flow.

The extraluminal flow was greater than the luminal flow in mild ureteral stenosis, and it was devoted to the total flow rate even in severe stenosis, in which the luminal flow rate was greater than the extraluminal flow. In severe ureteral stenosis, achieving a sufficient and acceptable total urine flow is difficult with a high luminal flow and a low extraluminal flow. The total flow rate in the $4.57-\mathrm{mm}$ ureter with a $74 \%$ ureteral stenosis was $16-23 \mathrm{~mL} / \mathrm{h}$ and in the $5.39-\mathrm{mm}$ ureter with $74 \%$ ureteral stenosis the flow rate was $26-43 \mathrm{~mL} / \mathrm{h}$. The urine output over $24 \mathrm{~h}$ was $384-552 \mathrm{~mL}$ and $624-1032 \mathrm{~mL}$. Achieving a sufficient urine flow through a stented ureter in severe ureteral stenosis is not easy.

In mild ureteral stenosis or no stenosis, achieving a sufficient and acceptable urine flow was relatively easy through a stented ureter, especially with a smaller-sized double-J stent. In the 4.57-mm ureter, the peak total flow rates with 5-, 6-, 7-, and 8-Fr double-J stents were 63, 47, 35, and $26 \mathrm{~mL} / \mathrm{h}$, respectively, and the urine output totals over $24 \mathrm{~h}$ were 1512, 1128, 840, and $624 \mathrm{~mL}$, respectively. In the 5.39-mm ureter, the peak total flow rates with 5-, 6-, 7-, and 8-Fr double-J stents were 147, 116,92 , and $71 \mathrm{~mL} / \mathrm{h}$, respectively, and the urine output totals over $24 \mathrm{~h}$ were 3528, 2784, 2208, and $1704 \mathrm{~mL}$, respectively.

Brewer et al. [12] reported correlation between inner and outer diameters of the ureter stent and urine flow in the stented ureter in an in vivo study. Our study showed similar results, direct proportion, in luminal flow, but partially different results, inverse proportion, in extraluminal flow. In their study, the stent smaller than or equal to 7 Fr showed a direct proportion and the stent bigger than 7 Fr showed an inverse proportion. Our study supports their study findings regarding a decrease in extraluminal flow with bigger ureteral stents.

Ramsay et al. [24] examined the effects of a double-J stent on an unobstructed ureter and found that the practical in vitro flow capabilities of stents did not seem to theoretically apply in vivo due to increased urine flow around the stent secondary to dilatation of the ureteral lumen in response to the stent and that the stenting could limit urinary drainage. This result means that the double-J stent itself could be one of the obstacles causing insufficient urinary drainage, even though the stent is widely used for relieving disturbances in urinary drainage due to a ureteral stenosis. 
Here, we performed the simulation with solid ureter and solid stent models differently from that of the human body. This study also has some limitations. First, we did not consider peristalsis or passive ureteral dilatation in the CFD analysis and thus did not perform the fluid structure interaction (FSI) simulation. Second, the tubular ureter model used in the study had a discrepancy with an uneven or undulated ureter in humans. Third, the results could be different if there had been more than a single site of stenosis. Further studies using the FSI simulation or an undilated ureter model based on the human anatomy could elaborate on the current study. Moreover, in vitro or in vivo studies could help to verify the findings of this study.

\section{Conclusions}

This study showed that larger double-J stents were not favorable in achieving an acceptable urine flow through a stented ureter. When using DJS, it seems desirable to consider the degree of ureteral stenosis. In severe ureter stenosis, it was not easy to get sufficient and acceptable total urine flow with the high luminal flow and low extraluminal flow. In spite, smaller stents achieved relatively high urine flow. In mild ureter stenosis or no stenosis, it was relatively easy to get sufficient and acceptable urine flow through a stented ureter especially with smaller size of a double J stent. The larger DJS had better been designed with more side holes to smoothly bypass urine in the stenosis zone, so it seems that sufficient flow rate can be secured.

Author Contributions: Conceptualization: Y.H.C.; Data Curation: H.-H.K., K.-w.K.; Funding Acquisition: Y.H.C.; Methodology: S.B.L.; Writing-Original Draft Preparation: H.-H.K., Y.H.C., K.-w.K.; Writing-Review \& Editing: Y.B. All authors have read and agreed to the published version of the manuscript.

Funding: This research received no external funding.

Acknowledgments: This research was supported by grant No. 02-2019-8 from the Seoul National University Boramae Hospital Research Fund.

Conflicts of Interest: No conflicts of interest, financial or otherwise, are declared by the authors.

\section{References}

1. Vahidi, B.; Fatouraee, N.; Imanparast, A.; Moghadam, A.N. A mathematical simulation of the ureter: Effects of the model parameters on ureteral pressure/flow relations. J. Biomech. Eng. 2011, 133. [CrossRef] [PubMed]

2. Vahidi, B.; Fatouraee, N. A biomechanical simulation of ureteral flow during peristalsis using intraluminal morphometric data. J. Theor. Biol. 2012, 298, 42-50. [CrossRef] [PubMed]

3. Adamo, R.; Saad, W.E.; Brown, D.B. Management of nephrostomy drains and ureteral stents. Tech. Vasc. Interv. Radiol. 2009, 12, 193-204. [CrossRef]

4. Venkatesan, N.; Shroff, S.; Jayachandran, K.; Doble, M. Polymers as ureteral stents. J. Endourol. 2010, 24, 191-198. [CrossRef] [PubMed]

5. Al-Aown, A.; Kyriazis, I.; Kallidonis, P.; Kraniotis, P.; Rigopoulos, C.; Karnabatidis, D.; Petsas, T.; Liatsikos, E. Ureteral stents: New ideas, new designs. Ther. Adv. Urol. 2010, 2, 85-92. [CrossRef]

6. Haleblian, G.; Kijvikai, K.; La Rosette, J.; Preminger, G. Ureteral stenting and urinary stone management: A systematic review. J. Urol. 2008, 179, 424-430. [CrossRef]

7. Chung, H.H.; Kim, M.D.; Won, J.Y.; Won, J.H.; Cho, S.B.; Seo, T.S.; Park, S.W.; Kang, B.C. Multicenter experience of the newly designed covered metallic ureteral stent for malignant ureteral occlusion: Comparison with double J stent insertion. Cardiovasc. Interv. Radiol. 2014, 37, 463-470. [CrossRef]

8. Makramalla, A.; Zuckerman, D.A. Nephroureteral stents: Principles and techniques. In: Seminars in interventional radiology. Thieme Med Publ. 2011, 28, 367-379. [CrossRef]

9. Finney, R.P. Experience with new double J ureteral catheter stent. J. Urol. 1978, 120, 678-681. [CrossRef]

10. Finney, R.P. Double-J and diversion stents. Urol. Clin. North Am. 1982, 9, 89-94.

11. Hendlin, K.; Vedula, K.; Horn, C.; Monga, M. In vitro evaluation of ureteral stent compression. Urology 2006, 67, 679-682. [CrossRef] [PubMed] 
12. Brewer, A.V.; elbahnasy, A.M.; Bercowsky, E.; Maxwell, K.L.; Shalhav, A.L.; Kahn, S.A.; Mcdougall, E.M.; Clayman, R.V. Mechanism of ureteral stent flow: A comparative in vivo study. J. Endourol. 1999, 13, $269-271$. [CrossRef] [PubMed]

13. Kim, H.H.; Choi, Y.H.; Lee, S.B.; Baba, Y.; Kim, K.W.; Suh, S.H. Numerical analysis of the urine flow in a stented ureter with no peristalsis. Bio-Med. Mater. Eng. 2015, 26, S215-S223. [CrossRef] [PubMed]

14. McFedries, P. Formulas and Functions with Microsoft Office Excel USA. 2007.

15. Shokeir, A.A. The diagnosis of upper urinary tract obstruction. BJU Int. 1999, 83, 893-900. [CrossRef]

16. Kim, K.W.; Choi, Y.H.; Lee, S.B.; Baba, Y.; Kim, H.H.; Suh, S.H. Analysis of Urine Flow in Three Different Ureter Models. Comput. Math. Methods Med. 2017. [CrossRef]

17. Ansys Inc. ANSYS-CFX Release 16; Ansys Inc.: Canonsburg, PA, USA, 2016.

18. Clavica, F.; Zhao, X.; ElMahdy, M.; Drake, M.J.; Zhang, X.; Carugo, D. Investigating the flow dynamics in the obstructed and stented ureter by means of a biomimetic artificial model. PLoS ONE 2014, 9, e87433. [CrossRef]

19. Kim, K.W.; Kim, H.H.; Choi, Y.H.; Lee, S.B.; Baba, Y. Urine flow analysis using double J stents of various sizes in in vitro ureter models. Int. J. Numer. Methods Biomed. Eng. 2020, e3294. [CrossRef]

20. Lopez-Martinez, R.A.; Singireddy, S.; Lang, E.K. The use of metallic stents to bypass ureteral strictures secondary to metastatic prostate cancer: Experience with 8 patients. J. Urol. 1997, 158, 50-53. [CrossRef]

21. Kinn, A.C.; Lykkeskov-Andersen, H. Impact on ureteral peristalsis in a stented ureter. An experimental study in the pig. Urol. Res. 2002, 30, 213-218. [CrossRef]

22. Venkatesh, R.; Landman, J.; Minor, S.D.; Lee, D.I.; Rehman, J.; Vanlangendonck, R.; Ragab, M.; Morrissey, K.; Sundaram, C.P.; Clayman, R.V.; et al. Impact of a double-pigtail stent on ureteral peristalsis in the porcine model: Initial studies using a novel implantable magnetic sensor. J. Endourol. 2005, 19, 170-176. [CrossRef]

23. Patel, U.; Kellett, M.J. Ureteric drainage and peristalsis after stenting studied using colour Doppler ultrasound. Br. J. Urol. 1996, 77, 530-535. [CrossRef] [PubMed]

24. Ramsay, J.W.A.; Payne, S.R.; Gosling, P.T.; Whitfield, H.N.; Wickham JE, A.; Levison, D.A. The effects of double J stenting on unobstructed ureters. An experimental and clinical study. Br. J. Urol. 1985, 57, 630-634. [CrossRef] [PubMed]

(C) 2020 by the authors. Licensee MDPI, Basel, Switzerland. This article is an open access article distributed under the terms and conditions of the Creative Commons Attribution (CC BY) license (http://creativecommons.org/licenses/by/4.0/). 